\title{
ПЕРСПЕКТИВЫ РАЗВИТИЯ ТУРИСТИЧЕСКОГО ПОТЕНЦИАЛА УЗБЕКИСТАНА
}

\author{
Гаибназарова Зумрат Талатовна ${ }^{1}$ \\ к.э.н., доцент \\ ТГТУ имени И.Каримова, \\ Инженерно-технологический факультет \\ (2.Ташкент, Узбекистан)
}

\begin{abstract}
Аннотация
B cтатье рассматриваются состояние $u$ перспективы развития туризма в Узбекистане, а также вылвлены основные причины, затрудняющие ускорение развития сферы туризма и эффективного использования туристского потенцииала в республике, $u$ приведень задачи для достижения цели государственной политики в сфере туризма.
\end{abstract}

Ключевые слова: туризм, мировая туриндустрия, государственная туристическая политика, международные туристические прибытия и рынок.

JEL коды: L 830.

В настоящее время на развитие туризма оказывают различное влияние ряд факторов, имеющих место в рамках всемирного процесса глобализации. Налицо глубокая геополитическая трансформация мира, требующая новых подходов к обеспечению стабильного и безопасного развития не только в отдельных регионах, но и в целом в мировом сообществе. Процесс глобализации способствует не только расширению интеграционных возможностей, но и углублению дифференциации стран по уровню доходов, появлению угроз, негативно влияющих на системы международных коммуникаций, в том числе, на развитие международного туризма.

Проблема туристического обмена особо актуализируется в связи с тем, что туризм представляет собой вид деятельности, который непосредственно влияет не только на внутренние составляющие развития отдельных стран, на их социально-экономическую, культурную, образовательную сферы деятельности, но и на состояние международных экономических, научно-технических, гуманитарных отношений. В связи с тем, что туризм

${ }^{1}$ Гаибназарова 3.T., e-mail: zumrat59@ rambler.ru 
охватывает широкий диапазон услуг и выходит за рамки традиционного представления о нем как о явлении, связанном исключительно с отдыхом, то и эффект от него должен рассматриваться с точки зрения влияния на различные сферы жизнедеятельности государств, их регионов, отдельных категорий населения.

По данным Всемирной туристической организации (ЮНВТО), туризм занимает четвертое место в мировом экспорте товаров и услуг, а по доходности - третье место. Его доля в мировом ВВП составляет $10 \%{ }^{1}$.

«Принимая во внимание динамичный рост туризма, его ощутимое мультипликативное воздействие на другие секторы экономики, рост благосостояния населения и необходимость принятия мер по охране окружающей среды, туристская отрасль должна стать одним из мощных инструментов повышения устойчивости развития страны», - отмечается в Концепции развития туристической отрасли Республики Узбекистан на среднесрочную перспективу ${ }^{2}$.

23 декабря 2016 г. в Самарканде состоялось выездное заседание Комитета по международным делам и межпарламентским связям Законодательной палаты Олий Мажлиса Республики Узбекистан, посвященное исполнению Закона Республики Узбекистан «О туризме» в Самаркандской области. На заседании отмечалось, что на территории Самаркандской области расположен 1851 объект материально-культурного наследия, из них: 1105 археологических, 670 архитектурных, 37 достопримечательных, 18 монументальных, 21 мемориальный. Благодаря оказанной туристическим фирмам государственной поддержке, за последние 4 года в области приобретено более 80 современных автобусов туристического класса. В целях создания дополнительных удобств для иностранных туристов в 20 гостиницах области установлены терминалы, обслуживающие международные кредитные карточки «Visa», «MasterCard» ${ }^{3}$. В целом за последние несколько лет в регионах республики была сформирована определенная система организации туристической деятельности, включающая в себя различные туристические фирмы и организации. Динамика количества обслуженных ими за последние годы граждан, представлена ниже на рисунке 1 и в таблице 1.

\footnotetext{
${ }^{1}$ Газета.uz (2017).

2 http://uzbektourism.uz/ru/

3 Пресс-служба Государственного комитета Республики Узбекистан по развитию туризма (2016).
} 


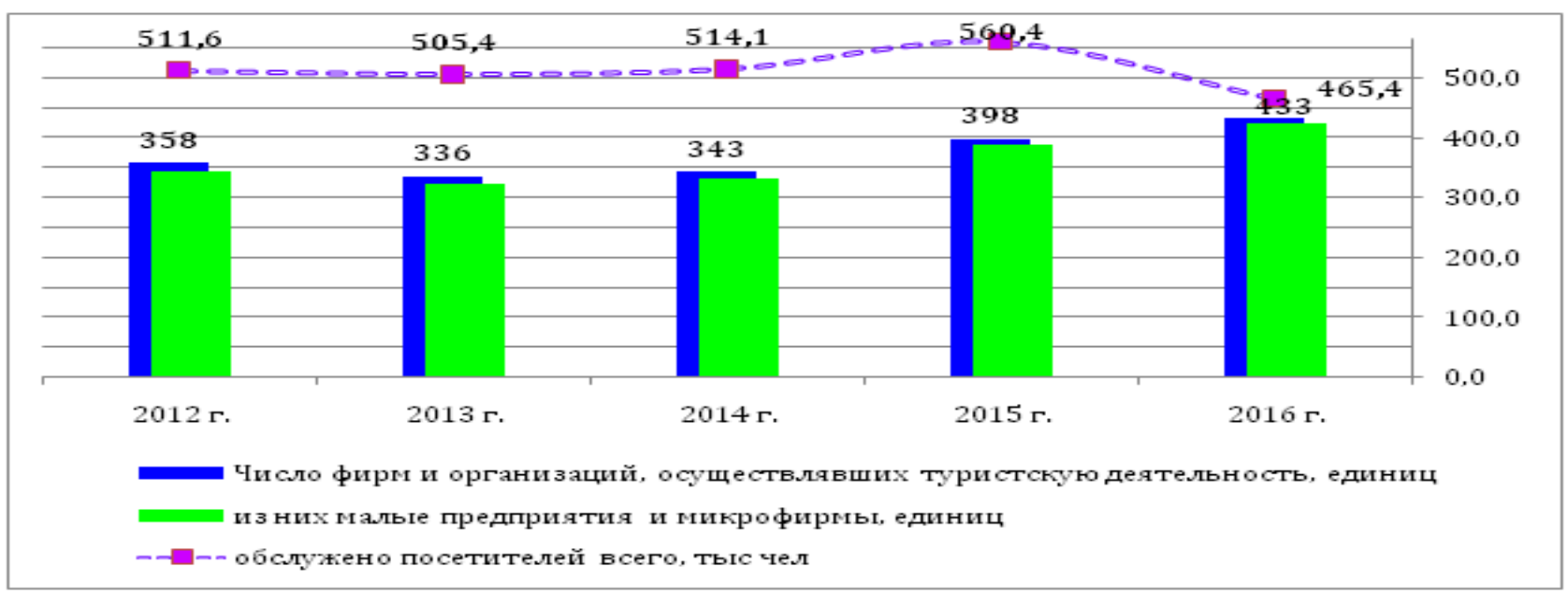

Рисунок 1. Число организаций, осуществлявших туристическую деятельность и лица, которым были оказаны услуги (2012-2016 гг. $)^{4}$

В 2016 г. число действующих туристических фирм составило 433 единицы, по сравнению с 2012 г. на 75 фирм больше. Число лиц, которым были оказаны туристические услуги в 2012 г., составило 511,6 тысяч человек, а в 2016 г. - 465,4 тысячи.

Таблиияа 1.

Число и стоимость проданных туров за 2016 год 5

\begin{tabular}{|l|c|c|}
\hline \multicolumn{1}{|c|}{ Описание } & \multicolumn{1}{|c|}{$\begin{array}{c}\text { Количество, } \\
\text { единиц }\end{array}$} & $\begin{array}{c}\text { Стоимость, } \\
\text { млн сумм }\end{array}$ \\
\hline Реализовано туров (путевок), всего & 103093 & 100906,1 \\
\hline Из них непосредственно населению & 101703 & 99431,3 \\
\hline в том числе: & & 17996,3 \\
\hline $\begin{array}{l}\text { Гражданам Узбекистана по территории } \\
\text { Узбекистана }\end{array}$ & 44763 & 12797,4 \\
\hline $\begin{array}{l}\text { Гражданам Узбекистана по зарубежным } \\
\text { странам }\end{array}$ & 15194 & 1971,0 \\
\hline $\begin{array}{l}\text { Гражданам СНГ по территории } \\
\text { Узбекистана }\end{array}$ & 9942 & 56666,6 \\
\hline $\begin{array}{l}\text { Гражданам других зарубежных стран } \\
\text { (кроме стран СНГ) по территории } \\
\text { Узбекистана }\end{array}$ & 31804 & \\
\hline
\end{tabular}

В 2016 г. 98,7 процентов проданных туров (101,7 тысяч штук) непосредственно были куплены населением. В частности, гражданам Узбекистана по территории Узбекистана было

${ }^{4}$ Статистический сборник (2017).

${ }^{5}$ Статистический сборник (2017). 
продано 44,8 тысяч туров (44,0 процента), гражданам СНГ - 9,9 тысяч туров (9,8 процентов), гражданам других зарубежных стран - 31,8 тысяч туров (31,3 процента). В частности, было продано гражданам Узбекистана 15,2 тысячи туров в зарубежные страны.

Одним из приоритетов проводимой комплексной работы является развитие туризма в регионах республики. В этой связи на законодательном уровне определены полномочия органов государственной власти на местах в сфере туризма. Так, согласно статье 7 Закона Республики Узбекистан «О туризме»: «Органы государственной власти на местах в сфере туризма разрабатывают и реализуют региональные программы развития туризма и решают иные вопросы в соответствии с законодательством ${ }^{6}$. В Законе Республики Узбекистан «Об охране и использовании объектов культурного наследия〉 определены полномочия органов государственной власти на местах по выявлению, осуществлению учета, охране, сохранению и использованию объектов культурного наследия, находящихся на их территории ${ }^{7}$. Конкретные меры по развитию туризма в регионах республики предусмотрены в Постановлении Президента Республики Узбекистан «О дополнительных мерах по ускоренному развитию сферы услуг и сервиса в сельской местности в 2013-2016 гг.».

В целях дальнейшего развития туристической инфраструктуры республики в соответствии с современными требованиями Кабинет Министров Республики Узбекистан утвердил адресные списки строительства и реконструкции санитарно-гигиенических узлов по типовому проекту, ввод которых предусматривается на территориях, прилегающих к объектам культурного наследия и культурно-развлекательным учреждениям в Андижанской, Бухарской, Навоийской, Наманганской, Самаркандской, Сурхандарьинской, Ферганской, Хорезмской областях и в городе Ташкенте 9 . Были приняты Постановления Кабинета Министров Республики Узбекистан, в рамках которых реализовывались специальные Программы, конкретные мероприятия, направленные на развитие сферы туризма в Кашкадарьинской, Сырдарьинской, Ташкентской, Хорезмской областях ${ }^{10}$. Огромная работа проведена в центрах туриндустрии Узбекистана. В частности, в рамках подготовки к 2750-летию города Самарканда, которое отмечалось в 2007 г., была проведена полная реконструкция и реставрация мавзолеев Амира Темура, Рухобод, комплекса Регистан, мечетей Хазрати Хызр и Бибихоним, памятника Шахи-Зинда, обсерватории Мирзо Улугбека ${ }^{11}$.

Важным показателем, характеризующим состояние туриндустрии в стране, ее регионах, является наличие и эффективность использования гостиниц (рис. 2 и 3).

\footnotetext{
${ }^{6}$ Ведомости Олий Мажлиса Республики Узбекистан, 1999, с. 227.

${ }^{7}$ Ведомости Олий Мажлиса Республики Узбекистан, 2001, с. 180.

${ }^{8}$ Собрание законодательства Республики Узбекистан, 2013, с. 216.

${ }^{9}$ Собрание законодательства Республики Узбекистан, 2015, с.114.

${ }^{10}$ Пресс-служба Государственного комитета Республики Узбекистан по развитию туризма (2016).

${ }^{11} \mathrm{http}: / / \mathrm{uza}$.uz/ru/tourism/samarkand-prinimaet-vsemirniy-turisticheskiy-forum
} 
Научные исследования экономического факультета. Электронный журнал. Том 10. Выпуск 1.

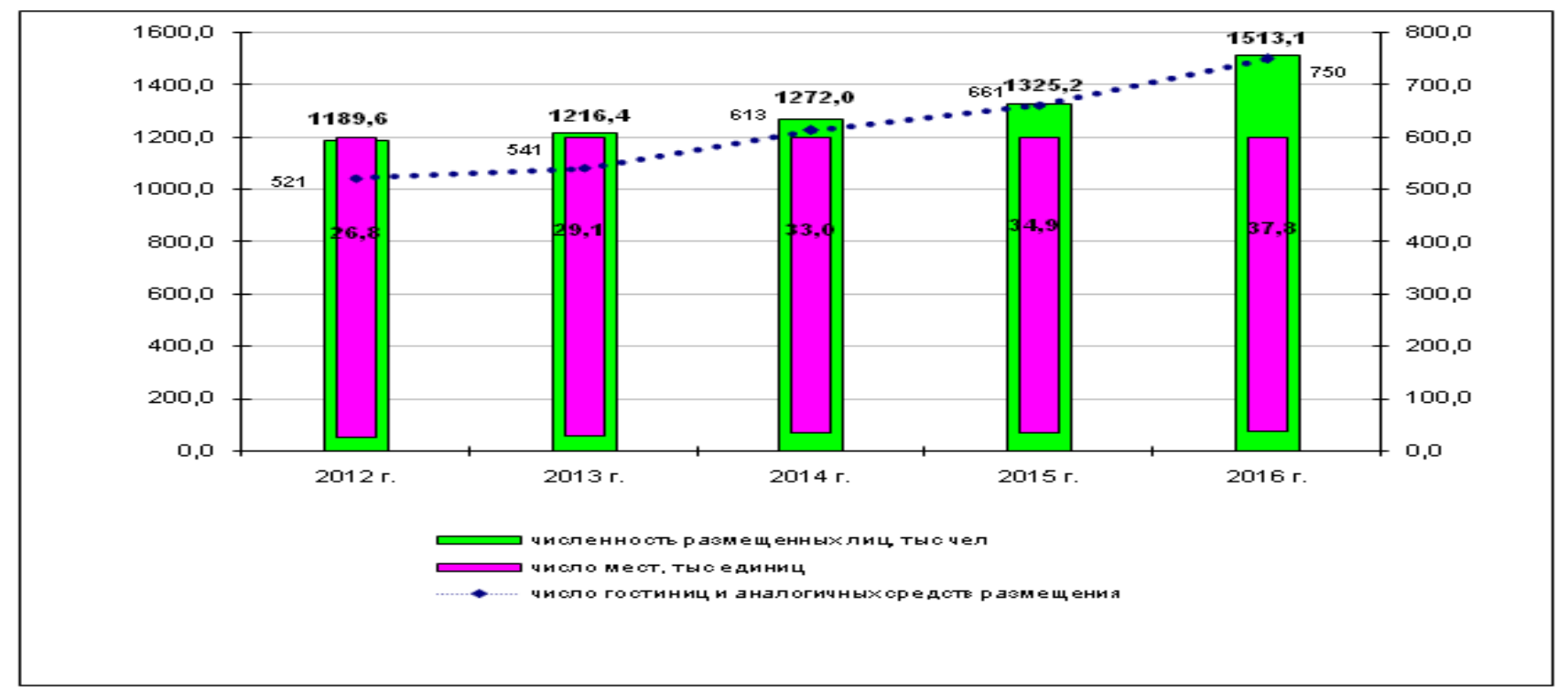

Рисунок 2. Гостиницы и аналогичные средства размещения по Республике Узбекистан (2012- 2016 гг. $)^{12}$

В 2016 г. число гостиниц и аналогичных средств размещения составили 750, по сравнению с 2012 г. увеличилось на 44,0 процента (229 единиц). Число мест в них увеличилось в 2012 г. на 40,8 процентов на 11 тысяч мест и составило 37,8 тысяч мест. Численность размещенных лиц в гостиницах 2016 г. составила 1513,1 тысячи человек, по сравнению с 2012 г. увеличилось на 27,2 процента (323,5 тысяч человек).

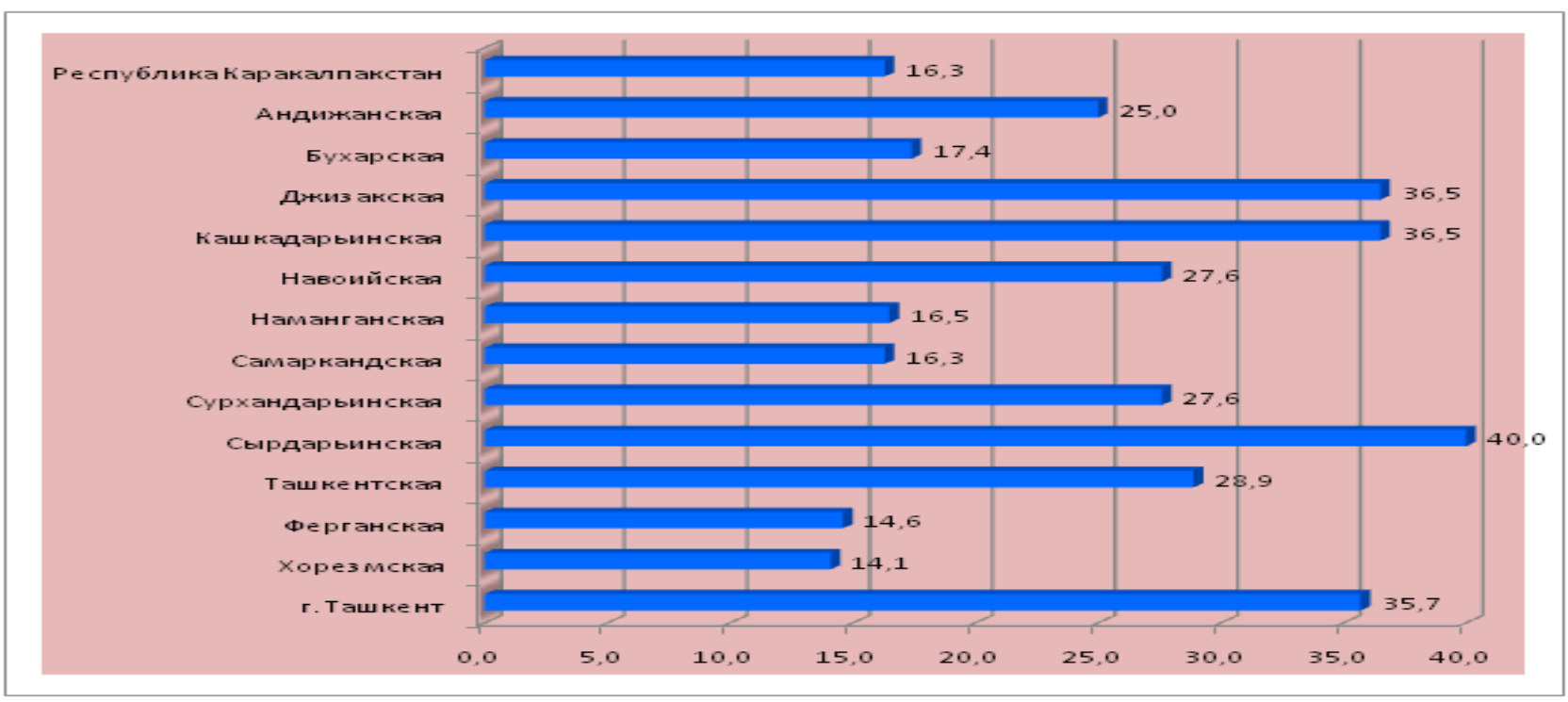

Рисунок 3. Коэффициент загрузки номерного фонда гостиниц и аналогичных средств размещения по регионам (в процентах) $)^{13}$

Однако в связи с быстрыми темпами развития мирового туристического рынка, на сегодняшний день все еще остаются нерешенными многие задачи по совершенствованию

\footnotetext{
12 Статистический сборник (2017).

${ }^{13}$ Статистический сборник (2017).
} 
туристической отрасли и превращения ее в локомотив для ускоренного комплексного развития регионов и сопряжённых с ней отраслей ${ }^{14}$.

Государственный комитет по развитию туризма разработал проект Стратегии развития туризма, в документе перечислены основные проблемы, мешающие развитию этого направления национальной экономики.

Потенциал узбекского туризма не реализуется полностью, так как развитие этой сферы напрямую зависит от формирования современного конкурентоспособного туристического комплекса с необходимой инфраструктурой транспортно-логистической системы.

Поэтому, по мнению экспертов, необходимо провести реконструкцию пунктов пропуска через Государственную границу (авиационных, автомобильных, железнодорожных) и усовершенствовать процесс пересечения границы, сделав его соответствующим потребностям иностранных граждан в туристических услугах.

Среди основных сдерживающих факторов увеличения потока туристов эксперты называют высокие цены на авиаперевозки, низкое покрытие потенциальных рынков отечественным и международными авиалиниями, а также визовую политику и систему регистрации в Узбекистане.

В числе других проблем - слабое развитие транспортной, социальной и инженерной инфраструктуры, труднодоступность и невысокий уровень сервиса в местах отдыха, неразвитость объектов придорожной инфраструктуры.

Еще одно проблемное место - недостаток квалифицированных кадров в сфере, отдаленность образовательных программ от требований рынка труда, потребностей производства, ожиданий работодателей.

В документе также отмечается, что сегодня в республике не развито нормативное регулирование сферы туризма и гостиничного бизнеса. В частности, в законодательстве отсутствуют стандарты, применяемые к определенным типам мест размещения, правила регулирования социального туризма, меры налогового стимулирования туристической отрасли.

Кроме того, подчеркивается, что на данный момент Узбекистан неизвестен в качестве туристического направления для большинства туристов из-за отсутствия агрессивной многоцелевой PR-стратегии страны.

При этом одним из важнейших условий устойчивого развития туризма эксперты называют государственную поддержку. Доходы от туризма, как прямые, так и косвенные,

\footnotetext{
${ }^{14}$ http://uzbektourism.uz/ru/
} 
довольно быстро окупают затраты на его развитие, что делает туристическую индустрию одним из наиболее важных двигателей социально-экономического развития страны ${ }^{15}$.

По оценкам Всемирного совета по туризму и путешествиям (ВСТП), Узбекистан занимает 150-е место среди стран мира по туристическим прибытиям (на его долю приходится 0,2\% от общего потока при оценочном потенциале в 2,2\%), 115-е - по совокупному вкладу в формирование ВВП страны, 103-е - по использованию инвестиций и 69-е - по числу занятых в отрасли ${ }^{16}$.

С учетом указанных проблем, в Узбекистане предпринимаются действенные меры в организационно-правовой, экономической, финансовой и других сферах функционирования туризма. Комплекс мер, направленных на кардинальные изменения в туристской отрасли Узбекистана предусмотрен в Указе Президента Республики Узбекистан «О мерах по обеспечению ускоренного развития туристской отрасли Республики Узбекистан» №УП-4861 от 2 декабря 2016 г. В частности, создан Государственный комитет Республики Узбекистан по развитию туризма на базе упраздненной Национальной компании «Узбектуризм» ${ }^{17}$. Указом предусматривается ${ }^{18}$ :

- ускоренное развитие, наряду с традиционным культурно-историческим туризмом, других потенциальных видов туризма - паломнического, экологического, познавательного, этнографического, гастрономического, спортивного, лечебно-оздоровительного, сельского, промышленного, делового и иных видов туризма;

- ускоренное развитие во всех регионах республики объектов туристической индустрии, отвечающих современным мировым стандартам, потребностям и требованиям туристов, гостиниц и аналогичных средств размещения, объектов общественного питания, транспортно- логистических структур, информационных центров, учреждений культуры и спорта, опережающее строительство и реконструкцию дорожно-транспортной и инженернокоммуникационной инфраструктуры, придорожной инфраструктуры по основным туристическим маршрутам, широкое привлечение для этих целей иностранных инвестиций;

- внесение в Кабинет Министров Концепции развития туристской отрасли Республики Узбекистан на среднесрочную перспективу.

Так, с 1 января 2017 г. лицензированию на право осуществления туристической деятельности подлежат только туристические предприятия, обеспечивающие организацию туристической деятельности, туристические операторы, туристические агентства, экскурсионные организации, туристические фирмы.

\footnotetext{
${ }^{15}$ Podrobno.uz (2018)

16 http://uzbektourism.uz/ru/

17 Собрание законодательства Республики Узбекистан, 2016, с. 559.

${ }^{18}$ Собрание законодательства Республики Узбекистан, 2016, с. 558, 2017, с. 3.
} 
В целях упрощения визовых процедур и создания благоприятных условий для посещения иностранными гражданами Республики Узбекистан с 1 января 2021 г. значительно упрощается визовый режим для граждан целого ряда стран ${ }^{19}$.

Программа конкретных мер по реализации Концепции развития туристской отрасли Республики Узбекистан в 2017-2021 гг. предусматривает реализацию мер по следующим направлениям ${ }^{20}$ : совершенствование нормативно-правового регулирования в сфере туризма; диверсификация туристического продукта и создание новых туристических маршрутов, мотивация и стимулы для привлечения туристов; развитие логистики, транспортной и придорожной инфраструктуры; развитие и поддержка деятельности средств размещения и других объектов туристической инфраструктуры; продвижение национального туристического продукта на внутреннем и внешнем рынках; меры по развитию внутреннего туризма; подготовка, переподготовка и повышение квалификации кадров в сфере туризма.

Банкам будет предложено выделять субъектам предпринимательства долгосрочные кредиты (15-20 лет) на строительство и модернизацию гостиниц с гибкими условиями погашения. Предусматривается значительное увеличение количества банкоматов и терминалов, работающих с международными платежными системами.

В целом ожидаемыми конечными результатами реализации Концепции является создание эффективного конкурентоспособного туристического комплекса Республики Узбекистан, который станет опорной точкой развития регионов и межрегиональных связей, активизировав вокруг себя развитие малого и среднего бизнеса (рост инвестиций в основной капитал туристической индустрии, увеличение произойдет за счет ввода новых и реконструкции действующих средств размещения, создания новых туристических фирм).

Основные результаты развития туризма в стране, выраженные в целевых показателях на период до 2021 г., приведены в табл. 2.

Таблица 2.

Ожидаемые результаты развития туризма в Республике Узбекистан, выраженные в целевых показателях ${ }^{21}$

\begin{tabular}{|c|c|c|c|c|c|c|}
\hline Показатели & 2016 & 2017 & 2018 & 2019 & 2020 & 2021 \\
\hline $\begin{array}{l}\text { Инвестиции в основной капитал } \\
\text { туристской индустрии, млрд сумм }\end{array}$ & 46,4 & 48,7 & 51,6 & 56,8 & 65,3 & 75,8 \\
\hline $\begin{array}{l}\text { Рост численности въехавших в РУз. } \\
\text { иностранных посетителей, тыс. чел. }\end{array}$ & 1979,1 & 2048,3 & 2130,3 & 2236,8 & 2371,0 & 2525,1 \\
\hline Количество гостиниц и других средств & 622 & 680 & 744 & 819 & 917 & 1036 \\
\hline
\end{tabular}

${ }_{19}$ Собрание законодательства Республики Узбекистан, 2016, с. 558, 2017, с. 3.

${ }^{20}$ http://uzbektourism.uz/ru/

${ }^{21} \underline{\mathrm{http}: / / \text { uzbektourism.uz/ru/ }}$ 


\begin{tabular}{|l|c|c|c|c|c|c|}
\hline \multicolumn{1}{|c|}{ Показатели } & $\mathbf{2 0 1 6}$ & $\mathbf{2 0 1 7}$ & $\mathbf{2 0 1 8}$ & $\mathbf{2 0 1 9}$ & $\mathbf{2 0 2 0}$ & $\mathbf{2 0 2 1}$ \\
\hline размещения, ед. & & & & & & \\
\hline $\begin{array}{l}\text { Количество субъектов туристской } \\
\text { деятельности, туроператоров }\end{array}$ & 418 & 441 & 467 & 498 & 530 & 565 \\
\hline $\begin{array}{l}\text { Экспорт туристских услуг, млн долл. } \\
\text { США }\end{array}$ & 1336,5 & 1510,2 & 1721,7 & 1979,9 & 2316,5 & 2721,9 \\
\hline
\end{tabular}

Туризм, на наш взгляд, это хорошая возможность социальной поддержки всех слоев населения, тем более, если он будет активно развиваться в регионах, кишлаках, находящихся в самых живописных местах республики. Этому будут способствовать вышеупомянутые специальные программы, важные меры, предпринимаемые в последнее время по совершенствованию нормативной базы функционирования туристической индустрии, реформированию системы управления туризмом, повышению эффективности деятельности туристических организаций, для каждого региона включенные конкретные мероприятия по развитию внутреннего и внешнего туризма в областях и селах, в этих проектах учитывают внутренние возможности и потенциал каждого региона, они будут способствовать обеспечению стабильного экономического роста отрасли, расширению разносторонних связей страны с другими государствами, повышению международного авторитета Узбекистана.

В заключение хотелось бы отметить, что будут способствовать укреплению современного высокоэффективного и конкурентоспособного туристического комплекса, расширению возможностей для удовлетворения потребностей туристов за счет высокого качества и разнообразия линейки туристических продуктов регионов Узбекистана и интенсификации его продвижения на зарубежные потребительские рынки, следующие меры:

- выработка модели туризма, исходя из потенциала регионов, сочетающая в себе традиции узбекского гостеприимства и западные стандарты обслуживания;

- комплексное развитие туризма на основе поддержки предпринимательства и выбора оптимальных методов государственного регулирования отрасли в регионах;

- формирование имиджа Узбекистана как привлекательной туристической страны;

- обеспечение создания новых рабочих мест в регионах, устойчивого притока иностранной валюты в экономику страны, развитие смежных секторов экономики, увеличение доли туризма в ВВП страны;

- увеличение инвестиций в человеческий капитал;

- сохранение природных и культурных ресурсов регионов для их использования как сейчас, так и в будущем;

- решение проблем адресного социального туризма, его доступности для малообеспеченных слоев населения;

- стимулирование въездного и внутреннего туризма;

- создание действенной информационной сети как определяющего фактора в разработке общей политической линии и стратегии развития туризма в регионах;

- обеспечение взаимодополняемости многочисленных элементов сектора туризма; 
Научные исследования экономического факультета. Электронный журнал. Том 10. Выпуск 1.

- создание условий для многоцелевого использования туристической инфраструктуры;

- регулирование рекламно-информационного и кадрового обеспечения;

- оптимизация экономических, экологических и социальных выгод от туризма с распределением этих выгод внутри общества, сведение к минимуму потенциальных проблем, связанных со становлением и функционированием индустрии туризма;

- координацию деятельности государственного и частного сектора в развитии туризма.

\section{Список литературы}

Закон Республики Узбекистан №830-І от 20.08.1999 г. «О туризме» // Ведомости Олий Мажлиса Республики Узбекистан. 1999. № 9. С. 227.

Закон Республики Узбекистан №269-II от 30 августа 2001 г. «Об охране и использовании объектов культурного наследия» // Ведомости Олий Мажлиса Республики Узбекистан. 2001. № 9-10. С. 180.

Заседание Комитета по международным делам и межпарламентским связям Законодательной палаты Олий Мажлиса Республики Узбекистан в Самарканде. Прессслужба Государственного комитета Республики Узбекистан по развитию туризма. 23 декабря 2016 г.

Названы главные проблемы развития туризма в Узбекистане // Podrobno.uz. 5 июля 2018 г.

Обсуждается проект Концепции развития туризма // Газета.uz. 2017. 22 февраля.

Постановление Президента Республики Узбекистан №ПП-1957 от 17 апреля 2013 г. «О дополнительных мерах по ускоренному развитию сферы услуг и сервиса в сельской местности в 2013-2016 гг.» // Собрание законодательства Республики Узбекистан. 2013. № 16. С. 216.

Постановление Президента Республики Узбекистан «Об организации деятельности Государственного Комитета Республики Узбекистан по развитию туризма» №ПП-2666 от 2 декабря 2016 г. // Собрание законодательства Республики Узбекистан. 2016. № 49. С. 559.

Постановление Кабинета Министров Республики Узбекистан № 51 от 9 марта 2015 г. «О мерах по развитию придорожной и туристской инфраструктуры» // Собрание законодательства Республики Узбекистан. 2015. № 10. С. 114.

Туризм в Узбекистане: статистический сборник. Государственный комитет Республики Узбекистан по статистике. Т., 2017.

Указ Президента Республики Узбекистан «О мерах по обеспечению ускоренного развития туристской отрасли Республики Узбекистан» №УП-4861 от 2 декабря 2016 г. // Собрание законодательства Республики Узбекистан. 2016. № 49. С. 558. 2017. № 1. С. 3.

Проект Концепции развития туристической отрасли Республики Узбекистан на среднесрочную перспективу. Государственный комитет Республики Узбекистан по развитию туризма. - [Электронный ресурс]. Режим доступа: http://uzbektourism.uz/ru/

Самарканд принимает всемирный туристический форум. - [Электронный ресурс]. Режим доступа: http://uza.uz/ru/tourism/samarkand-prinimaet-vsemirnyy-turisticheskiy-forum 


\title{
PROSPECTS FOR THE DEVELOPMENT OF TOURISM POTENTIAL OF UZBEKISTAN
}

\author{
Zumrat Gaibnazarova \\ Candidate of economic sciences, Associate Professor \\ TSTU named after I.Karimov, \\ Faculty of Engineering Technology, \\ Department of Corporate governance, \\ (Tashkent, Uzbekistan)
}

\begin{abstract}
The article deals the state and trends of tourism development in Uzbekistan, as well as the main reasons that hamper the accelerated development of the tourism sector and the effective use of tourism potential in the republic and set objectives for achieving the goal of state policy in the field of tourism.
\end{abstract}

Key words: tourism, world tourism industry, state tourism policy, international tourist arrivals and market.

JEL codes: L 830. 